\title{
Goal Hierarchies as Antecedents of Market Structure
}

\author{
Marcel Paulssen \\ Humboldt University \\ Richard P. Bagozzi \\ The University of Michigan
}

\begin{abstract}
Current models of market structure are descriptive in nature and lack theoretical grounding in consumer behavior. Such grounding is especially needed in the specification of marketing strategies. A self-regulatory model of consumer consideration-set formation will be employed as a basis of market structure in this article. The authors propose and show that consumers regulate their behavior according to goals at different levels of their goal hierarchies, which in turn determine brand consideration. Differences in the salience of goals at different hierarchical levels lead to differences in the composition of consideration sets. It is precisely these individual differences in brand consideration that determine the structure of a market. The analysis of consumers' goal hierarchies therefore answers, in part, the question of why a market has a certain structure. Hypotheses on brand consideration and the role of system- and principle-level goals are tested on a sample of 1,018 consumers of automobiles. (C) 2006 Wiley Periodicals, Inc.
\end{abstract}

What is our market? Who are our customers? Who are our competitors? These are obvious but important research questions for every company. Key strategic issues such as basic business definition, opportunity assessment, threat analysis, or resource-allocation decisions all depend on the definition and structure of a market. A thorough understanding of a mar-

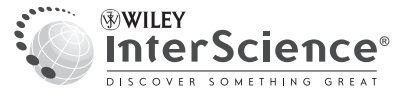


ket and its structure is therefore crucial for strategic as well as operative marketing decision making (Elrod et al., 2002). The goal of market structure analysis (MSA) is to provide this understanding of a market and its structure precisely, by explaining the nature and extent of competition among companies and their products.

Two approaches to market structure analysis can be distinguished: supply-side or demand-side approaches. Typically the criteria employed to operationalize market structure are used to classify the different approaches. Despandé and Gatignon (1994) distinguish three different approaches to market structuring: the analysis of actual purchases, the analysis of consumer judgments, and the analysis of firm strategies. Supply-side approaches, such as the analysis of firm strategies, are extensively discussed in the industrial organization literature on strategic groups (e.g., Porter, 1979). The focus of this article is on demand-side approaches that are based on the notion that the customer's perceived substitutability between products primarily constitutes competition and largely determines the structure of a market.

Even though a variety of methods for the analysis of market structure have been developed for different types of input data (see Cooper \& Inoue, 1996; Elrod et al., 2002), a shortcoming of most these approaches to market structuring is their descriptive nature. Ratneshwar, Shocker, Cotte, and Srivastava (1999) state that an important gap in current models of market structuring is their lack of a sound theoretical foundation in consumer behavior. Given that a thorough understanding of customer behavior should be a starting point of marketing decision making (e.g., Aaker, 1998; Hunt \& Morgan, 1995), this is an obvious shortcoming. Following the Ratneshwar et al. call (1999), the goal of this article is to develop a model of market structure that is built on a theory of individual consumer behavior. The objective is to provide a richer understanding of why a market has a certain structure, rather than merely describing or mapping its structure, per se. Building on recent research in MSA, the proposed model of individual consumer behavior is based on the notion that consumer behavior is goal-directed and purposive (Ratneshwar et al., 1999; Yang, Allenby, \& Fennell, 2002). A richer understanding of the behavioral determinants of market structure can help companies anticipate shifts in customer preferences that may alter their competitive advantage (Hunt \& Morgan, 1995).

\section{MODEL DEVELOPMENT}

\section{Market Structure with Consideration Sets}

As noted above, the focus of this article is on demand-side approaches to market structuring, where perceived substitutability from the consumer's perspective is the decisive criterion for delineating markets. Brands that comprise an individual consumer's consideration set are those brands 
he or she perceives as substitutes for a future purchase (Roberts \& Lattin, 1991). Only brands in the consideration set are seriously scrutinized in a purchase decision. Hence, the market for each consumer is individually restricted to his or her consideration set. Competition between goods or services exists to the extent that potential customers jointly consider them in a particular purchase occasion. The more consumers jointly consider two brands, the higher the degree of substitutability and thus the greater the intensity of competition between those two brands (Cooper \& Inoue, 1996; Siddarth et al., 1995). As Ratneshwar et al. (1999) state, “a focus on the composition of consumer's consideration sets is equally important: it provides competitor information relevant to a comparative assessment of the firm's resources and competencies. . ."

Several researchers have employed consideration sets to structure a market (e.g., De Sarbo \& Jedidi, 1995; Finn \& Louviere, 1990). De Sarbo and Jedidi (1995) define a market segment as a group of consumers who possess similar consideration sets. Their study employed latent structure models with the assumption of conditional independence to determine the number and composition of segments. This is in contrast to findings by Hauser and Wernerfeldt (1989), who show that probabilistic independence of brand consideration is, at least for the product category of their study, a reasonable assumption. The present article follows the proposal of De Sarbo and Jedidi (1995) that market segments can be conceptualized as latent types of consumers with homogeneous consideration sets. The probabilistic independence hypothesis confirmed by Hauser and Wernerfeldt (1989) essentially states that a market is unstructured or unpartitioned. All brands in the market compete with each other proportionally to their market share, and the whole market is one class or segment. The probabilistic independence hypothesis will be used as a null market structure hypothesis against which the market structure hypothesis proposed below will be tested:

H1: Brand consideration is conditionally independent given $c$ classes/ segments, with $c \geq 2$.

If the null market structure hypothesis can be rejected and $\mathrm{H} 1$ accepted, a number of classes/segments greater than 1 will be derived. Within these segments, brand consideration is probabilistically independent. What has been proposed so far is similar to the majority of market structure analyses which are purely descriptive. Below, a self-regulatory model of consideration set formation is introduced as a model of individual consumer behavior that will serve as a theoretical foundation for the proposed market structuring approach.

\section{The Self-Regulatory Model of Consideration-Set Formation}

Most of the research on consideration sets in memory-based choice examines retrieval processes and the role of cues in brand retrieval (e.g., 
Nedungadi, 1990; Nedungadi, Chattopadhyay, \& Muthukrishnan, 2001). Because alternatives might be recalled even though they may eventually become rejected, the investigation of retrieval processes basically looks at the formation of the awareness set and not the consideration set in a product category (Holden, 1993). In order to investigate the direct antecedents of memory-based consideration, Paulssen and Bagozzi (2005) developed a self-regulatory model of consideration set formation, which is based on the Carver and Scheier (1990) theory of self-regulation.

The self-regulatory model of consideration-set formation is based on the notion of goal-oriented, purposive behavior on the part of the consumer (Bagozzi \& Dholakia, 1999; Bagozzi \& Nataraajan, 2000). The model is consistent with recent research that stresses the role of consumer goals and purpose in models of market structure (Ratneshwar et al., 1999; Yang et al., 2002). In the theory of self-regulation, behavior is conceptualized as a self-regulatory process comprised of ongoing comparisons of one's present behavior with salient behavioral standards (Carver \& Scheier, 1996). Carver and Scheier proposed a three-tiered hierarchy of feedback loops. At the highest or system level, the ideal self can be a goal or reference value. The next lower level of control is termed the principle level. Here, people adopt guiding principles that are implied by the ideal self to which they aspire. Principle-level goals are implemented in the third level, termed the program level. A principle supports the person in making decisions about which programs of action to undertake and the necessary decisions to take while executing a particular program (Carver \& Scheier, 1990). Programs, in effect, provide behavioral content in which a principle can be reflected. Consideration sets can be conceptualized as programs because they provide behavioral content by specifying individually different means of goal-derived behavior, such as occurs for consideration of possible car brands to purchase by consumers (see Paulssen \& Bagozzi, 2005, for more detail). As an example (see top left part of Figure 1), "social recognition" might represent a consumer's salient higher-order goal when considering car brands (system level). Self-regulation with regard to one's system-level goal for social recognition involves comparison of one's desired or ideal social recognition to that actually achieved at any one particular point in time (see Comparator 3 in Figure 1). If a consumer's achieved social recognition falls below the standard, then a specific principle-level goal is selected as a reference value. For some consumers, for example, the benefits believed to be associated with "sporty driving" might be perceived as "enhancing social recognition," which then becomes a subordinate goal. The ideal self as a system goal determines principle-level goals. Thus, an unfavorable comparison between the subordinate goal, "sporty driving," and one's current state of "sporty driving" as a standard (see Comparator 2 in Figure 1) leads to the program level, which constitutes the formation of a goal-derived category and thus a consideration set, "cars that provide sporty driving." 


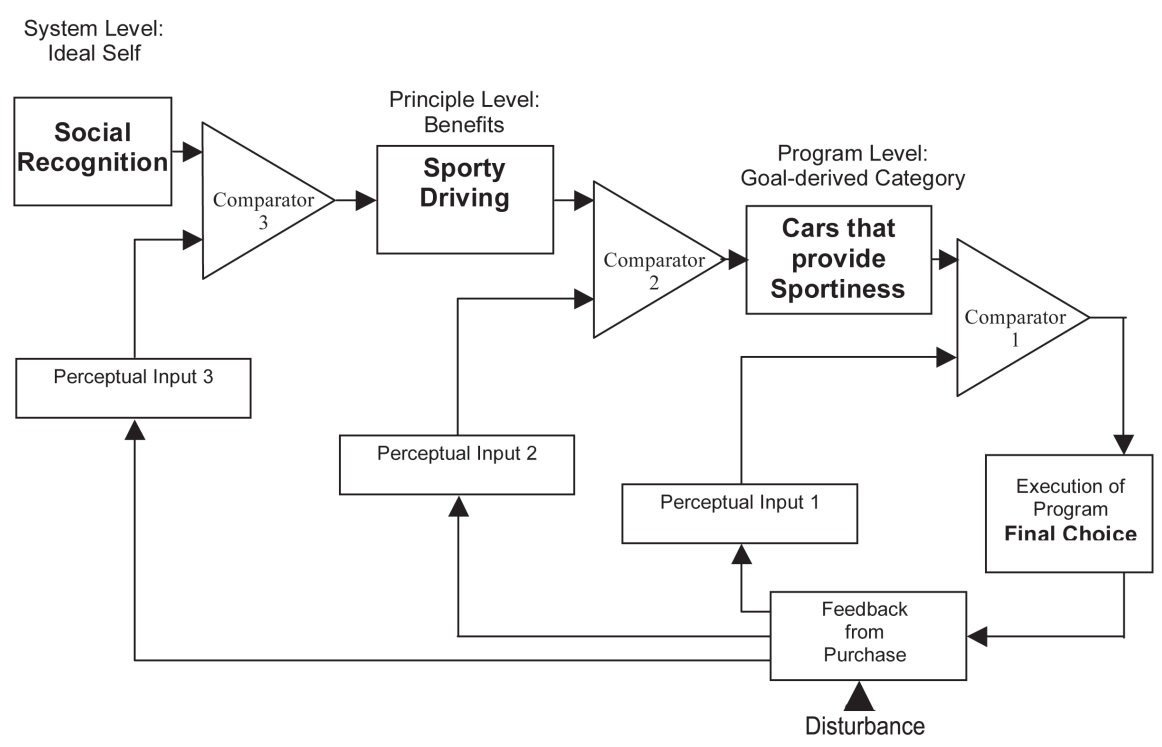

Figure 1. The self-regulatory model of consideration sets applied to the example of automobile purchase.

The self-regulatory model of consideration-set formation proposes that higher-order goals, such as the ideal self, determine benefits that in turn determine brand consideration through self-regulatory processes. In the aggregate, the composition of many individual consumer's consideration sets determines the degree of competition between brands in the marketplace, which is the structure of a market. Therefore, latent consumer types characterized by their pattern of brand categorizations should differ with respect to the salience of goals at different levels in their goal hierarchies. Different saliences of goals at the system and principle levels result in different patterns of brand categorization and are consequently the reason for the existence of different market segments, defined as latent consumer types with homogenous brand consideration. Thus

H2: The salience of system-level goals (the Ideal Self) differs across latent brand consideration types.

H3: The salience of principle-level goals (Benefits) differs across latent brand consideration types.

Structural relationships between system- and principle-level goals will not be proposed and tested (see, e.g., Paulssen \& Bagozzi, 2005). This article focuses instead on aggregate-level consequences of goal orientations. Thus the objective is to explore whether the structural relationships between system- and principle-level goals are invariant across latent brand consideration segments. 


\section{METHOD}

\section{Overview}

In this empirical study, brand consideration is investigated in the product category, cars. This category is an apt choice, because cars are highinvolvement products with a number of strong nonfunctional attributes and implications. Hence it is likely that consumer behavior will be controlled at the system level by such abstract goals as the Ideal Self (see Figure 1). Since market segments are conceptualized as latent types of consumers with homogeneous consideration sets, the focus of this study is on memory-based consideration sets. Therefore, respondents were selected who were actual car owners and familiar with the product category. These respondents should have already formed a consideration set to a certain extent, and considered car brands can be retrieved from memory in a simulated purchase situation. Given the focus on goals as ultimate determinants of market structure, other possible determinants, such as income or dealer proximity, will not be investigated (see, e.g., Punj \& Brookes, 2001).

\section{DATA AND DESCRIPTIVES}

A total of 1,018 respondents were interviewed in a survey by consumers in cooperation with a German car manufacturer. The survey questionnaires were administered in personal interviews and conducted by a major market research company. A disproportionate quota sampling based on car ownership was employed to select respondents. Only respondents who were actual car owners and had purchased a new car within the last 4 years were interviewed. Thus a consideration set had already been formed and considered brands could be retrieved from memory in the purchase situation under study. The characteristics of the sample can be described as follows: $77.3 \%$ were men, $22.7 \%$ women; the households had $1(20.1 \%), 2(33.2 \%), 3(25.6 \%), 4(17.5 \%)$, and 5 or more $(3.5 \%)$ persons; and $72.3 \%$ owned one car, $27.7 \%$ owned two or more cars.

\section{Operationalizing the Constructs}

The measurement scales of the theoretical constructs employed in this study were developed following the two-stage approach advocated by Anderson and Gerbing (1988). Following the recommendations of Fornell and Yi (1992a, 1992b), the measurement models were cross validated in a separate sample. Therefore, the sample was randomly split into calibration and validation samples.

Ideal Self. Schwartz's (1992) framework of motivational domains was used as a reference factor system from his theory of basic human values. 
Although the theory of basic human values has been broadly validated across countries and cultures (e.g., Schwartz \& Boehnke, 2004), so far few applications in the consumer-behavior domain have been done. Three motivational types from Schwartz's framework were measured as aspects of the ideal self and were thought to be especially relevant for the product category, cars: security/family security, power/social recognition, and self-direction/independence. Respondents had to answer 4-point scales that measured their ideal selves. The questions were phrased as follows: "I have cards with descriptions of persons. Please tell me for each description of a person how much you would like to be that person using the scale below." The scale ranged from very much to not at all. The authors tested and confirmed the validity of three proposed goal dimensions of the ideal self through confirmatory factor analyses. Again, the model was tested in calibration and validation samples (see Appendixes 1 and 2). The estimated factor loadings (lambda values) were all significant and substantial, indicating within-method convergent validity. The moderate construct intercorrelations, which are clearly significantly less than 1 , demonstrate discriminant validity. A full cross-validation of the model in the validation sample provided a good fit.

Benefits. Respondents were asked to rate the importance of 20 different benefits for the purchase of a new car. The question was phrased as follows: "Suppose you would buy a brand new car in the next couple of days. What importance would the aspects mentioned on these cards have for your personal decision for a new automobile. You can distribute between 1 and 10 points per aspect. The more important an aspect is for you personally, the more points you should distribute." The response format was a 10-point scale that ranged from totally unimportant (1 point) to very important (10 points). The 20 items for the benefit measurements used in this study were suggested by a German car manufacturer, which has done considerable research on benefits and uses these items regularly in its surveys. An initial exploratory factor analyses yielded a four-factor solution. Based on this and item-to-total correlations, indicators that did not clearly relate to a construct were eliminated. In this manner, the authors derived four key benefit constructs that were labeled as: safety, economy, sportiness, and comfort. The estimated lambda values for factor loadings were all significant and substantial. The construct intercorrelations were also significantly less than 1 as well. Thus, withinmethod discriminant and convergent validity were demonstrated. Unfortunately, comfort was only measured with one item, and therefore no reliability could be computed for it (see Appendix 1 for results of confirmatory factor analysis and composite reliabilities). A competing model where the benefit, comfort, was also measured through a second item had to be rejected because in the calibration sample, as well as in the validation sample, negative or nonsignificant error variances were estimated for the second item. A cross-validation with lambdas constrained 
to be equal across samples provided an acceptable fit with a nonsignificant test of close fit.

Consideration Sets. Consideration sets were measured with the following questions: "Assuming you would buy a brand new car in the next couple of days: Which brands and which models would you consider? Which cars would you take into account in your choice decision?" Respondents could list up to five brands (see Punj \& Brookes, 2001, 2003, for a similar approach). Because only $14.5 \%$ of the respondents considered more than four brands, the restriction of the consideration set to a maximum number of five brands seems appropriate. The average consideration set size was 2.33 and is in line with other studies for the category of cars (e.g., Gronhaug \& Troye, 1983).

\section{RESULTS}

Contrary to Hauser and Wernerfeldt (1989), who assumed probabilistic independence, it was assumed that brand consideration is not probabilistically independent. A latent class analysis was conducted to test H1 against the null market structure hypothesis (Clogg, 1995; Langeheine, 1988). Fifteen brands were considered by more than $1 \%$ of the respondents. However, as the number of cases was 1,018 , it was not possible to retain all brands in the analysis, because the ratio of cells to cases would have been 32 to 1 . Forman (1984) recommends as a minimum requirement that the number of cases should be greater than the number of cells. Thus, given a sample size of 1,018 , only 10 brands could be included in the analysis to satisfy the above-stated minimum condition. Brands were retained in the analysis based on their "share of mind," that is, the percentage of respondents who considered them in a purchase decision. The 10 brands with the highest share of mind were Mercedes Benz, BMW, Audi, Ford, Mazda, Opel, Renault, Toyota, Volkswagen, and Volvo. The five deleted brands had a mean share of mind of only $3.5 \%$ in the sample, and only one deleted brand had a share of mind above 5\% (i.e., 5.4\%). Thus the 10 brands capture a reasonably large share of mind for the sample at hand.

The resulting cross table has $1,024\left(2^{10}\right)$ cells, of which only 142 had nonzero elements. Given this high degree of sparseness, model evaluation with only chi-square-based statistics would be problematic (Collins, Fidler, Wugalter, \& Long, 1993; Langeheine, Pannekoek, and Van de Pol, 1996). As a consequence, parametric bootstrap simulations were conducted to assess model fit, in addition to chi-square-based statistics and information theoretic indices. Nonbootstrapped fit measures for latent class models with different numbers of classes are reported in Table 1. The one class model is essentially a test of the null market structure 
Table 1. Nonbootstrapped Measures of Fit for the 1993 Latent Class Model.

\begin{tabular}{lccccccccc}
\hline Model & $d f$ & $G^{2}$ & $P$ & $\mathrm{RC}$ & $P$ & $\chi^{2}$ & $p$ & $\mathrm{AIC}$ & $\mathrm{BIC}$ \\
\hline 1 Class & 1013 & 706.32 & 1.00 & 826 & 0.99 & 1084 & 0.058 & 8670 & 8768 \\
2 Class & 1002 & 390.06 & 1.00 & 436.45 & 1.00 & 545.19 & 1.00 & 8356 & 8459 \\
3 Class & 996 & 349.50 & 1.00 & 412.04 & 1.00 & 555.84 & 1.00 & 8327 & 8460 \\
4 Class & 988 & 314.91 & 1.00 & 374.18 & 1.00 & 507.17 & 1.00 & 8308 & 8481 \\
5 Class & 984 & 297.79 & 1.00 & 320.03 & 1.00 & 379.13 & 1.00 & 8299 & 8491 \\
\hline
\end{tabular}

Table 2. Bootstrapped Measures of Fit for the 1993 Latent Class Model.

\begin{tabular}{lcccc}
\hline Model & Number of Bootstrap Samples & $p\left(G^{2}\right)$ & $p(\mathrm{RC})$ & $p\left(\chi^{2}\right)$ \\
\hline 2 Class & 1,000 & 0 & 0.47 & 0.74 \\
3 Class & 1,000 & 0 & 0.33 & 0.49 \\
4 Class & 1,000 & 0 & 0.32 & 0.46 \\
5 Class & 1,000 & 0 & 0.66 & 0.81 \\
\hline
\end{tabular}

hypothesis that brand consideration of the 10 brands is probabilistically independent. Given the high degree of sparseness of the data, a stringent test of the null hypothesis with chi-square-based statistics is not possible. Another point to note is the issue of boundary solutions or parameters that are estimated to be 0 or 1 . Following the convention introduced by Goodman (1974), the degrees of freedom are adjusted for the number of boundary values (see also Van de Pol, Langeheine, \& De Jong, 1991, for a more elaborate discussion of this issue). As the degrees of freedom also enter the calculation of AIC and BIC, corrected values for these two indices are reported (see Table 2). For all estimated models, 100 random sets of starting values were evaluated to avoid local maxima. The models were estimated with the program PANMARK (Van de Pol et al., 1991).

According to the chi-square-based statistics, the null market structure hypothesis implicit in the one-class model cannot be rejected. All three statistics are not significant at $p<.05$. However, the values of the log-likelihood ratio $\left(G^{2}\right)$, the Read-Cressie statistic (RC), Pearson's chisquare, and corresponding $p$ values differ significantly. Such a result is to be expected in the presence of sparse data. In particular, the Pearson chi-square and the log-likelihood ratio differ, in that the former tends to be larger if several cells have model-expected frequencies much smaller than 1 (Langeheine et al., 1996). For the two-class model, all chisquare-based statistics indicate a perfect fit between model and data, although there is still a discrepancy in the absolute magnitude of the three statistics. Three-, four-, and five-class models also have a perfect fit with the data. The information-theoretic indices, AIC and BIC, are inconclusive, as the AIC has its minimum with the five-class model, and the $\mathrm{BIC}$ has its minimum with the two-class model. However, the BIC penalizes overparametrization more severely than the AIC and favors more par- 
simonious models (Dillon \& Kumar, 1994). Thus, a two-class model is the most parsimonious model that fits the data to an acceptable degree. Additionally, parametric bootstrap was applied to estimate a bootstrap $\alpha$. Following Langeheine, Van de Pol, and Pannekoek (1997), who concluded that stability of $p$ values is achieved with bootstrap samples of approximately 1000, bootstrap simulations were conducted with 1000 evaluated bootstrap samples (see Table 2).

The bootstrapped $p$ values are identical for the four models, as the bootstrapped log-likelihood ratio indicates rejection, whereas both ReadCressie and Pearson's chi-square indicate acceptance. Considering fit and parsimony of both bootstrapped and nonbootstrapped results, the twoclass model is favored. The predictive ability of the two-class model corroborates this conclusion. The percentage of respondents correctly allocated in the latent classes was $88 \%$, and the lambda measure of association (Clogg, 1979) was 0.72 for the two-class model. The corresponding values for the three- and four-class models were $83 \%$ and $84 \%$, and 0.63 and 0.65 , respectively. It could be argued that the manufacturer from a managerial perspective might have favored a more complex three- and fourclass solution. However, actionability of the market structure model is not the issue of this article and beyond the scope of the current research. The hypothesis that brand consideration is probabilistically independent could neither be safely rejected nor be accepted with a stringent statistical test. However, both the AIC and BIC indicate that the two-class model clearly fits the data better than the null market structure model, and this model will therefore be retained and interpreted (see Table 3).

In class/segment 1, the brands Mercedes Benz, BMW, Volvo, and to a lesser extent also Audi have relatively high probabilities of being considered in future purchase decisions. Thus the consumer type representing this segment can be labeled as "premium car buyer." In class/segment 2, the brands Ford, Mazda, Opel, Renault, Toyota, and Volkswagen are considered with a relatively high probability in future purchase decisions, whereas the probability of considering the brands Mercedes Benz, Volvo, and BMW is very low, and in fact in the case of the first two almost zero. The consumer type representing the second class/segment is therefore referred to as "mass car buyer." Brand consideration of all 10 brands included in the analysis discriminate very well between the two segments, except in the case of Audi.

In the following section, $\mathrm{H} 2$ and $\mathrm{H} 3$ are tested. As discussed in the section on construct operationalization, the ideal self was measured as system-level goals and benefits as principle-level goals. Before testing whether segments differ with respect to the salience of system and principle-level goals at which the respective consumers in the two segments regulate their behavior, an assessment was made whether goals are on the same scale across segments. Models were tested with LISREL 8.5 (Jöreskog \& Sörbom, 1996), with the use of the WLS estimator. Listwise deletion was conducted on cases with missing values, resulting in an effective sample 
Table 3. Size and Class-Specific Probabilities of Consideration for the TwoClass Model.

\begin{tabular}{|c|c|c|c|c|}
\hline Size $\longrightarrow$ & $\begin{array}{l}\text { Segment } 1 \\
0.562\end{array}$ & $\begin{array}{l}\text { Segment } 2 \\
0.438\end{array}$ & & \\
\hline Brand & $\begin{array}{l}\text { Class-Specific } \\
\text { Probability of } \\
\text { Consideration }\end{array}$ & $\begin{array}{l}\text { Class-Specific } \\
\text { Probability of } \\
\text { Consideration }\end{array}$ & $\begin{array}{c}\text { Sample } \\
\text { Probability }\end{array}$ & $\begin{array}{l}\text { Ratio of Largest } \\
\text { to Smallest } \\
\text { Class-Specific } \\
\text { Probability }\end{array}$ \\
\hline Mercedes Benz & 0.487 & 0.029 & 0.287 & 16.8 \\
\hline BMW & 0.518 & 0.109 & 0.339 & 4.8 \\
\hline Audi & 0.255 & 0.167 & 0.216 & 1.5 \\
\hline Ford & 0.024 & 0.221 & 0.110 & 9.2 \\
\hline Mazda & 0.022 & 0.135 & 0.072 & 6.1 \\
\hline Opel & 0.114 & 0.444 & 0.258 & 3.9 \\
\hline Renault & 0.022 & 0.107 & 0.059 & 4.9 \\
\hline Toyota & 0.045 & 0.117 & 0.077 & 2.6 \\
\hline Volkswagen & 0.091 & 0.469 & 0.256 & 5.2 \\
\hline Volvo & 0.107 & 0.009 & 0.064 & 11.9 \\
\hline
\end{tabular}

Table 4. Results of Multiple Group Analysis for the Self-Ideal Model.

\begin{tabular}{lccc}
\hline Model & Goodness of Fit & Test of Hypothesis \\
\hline M1: & $\begin{array}{c}\text { Equal factor } \\
\text { pattern }\end{array}$ & $\begin{array}{c}\chi\left(114, N_{1}=498, N_{2}=356\right)=231.90 \\
p=0.00 ; \mathrm{RMSEA}=0.049 ; \mathrm{CFI}=0.98\end{array}$ & - \\
\hline M2: & $\Lambda_{\mathrm{x}}$ invariant & $\chi\left(121, N_{1}=\begin{array}{c}\left.498, N_{2}=356\right)=239.61 \\
p=0.00\end{array}\right.$ & $\begin{array}{c}M_{2}-M_{1} \\
\chi_{d}^{2}(7)=7.71 \\
p>.05\end{array}$ \\
\hline M3: & $\begin{array}{l}\Lambda_{\mathrm{x}} \text { invariant } \\
\Theta_{\delta} \text { invariant }\end{array}$ & $\chi\left(134, N_{1}=498, N_{2}=356\right)=251.67$ \\
$p=0.00$ & $\begin{array}{c}M_{3}-M_{2} \\
\chi_{d}^{2}(13)=12.06 \\
p>.05\end{array}$ \\
\hline M4: & $\begin{array}{c}\Lambda_{\mathrm{x}} \text { invariant } \\
\Theta_{\delta} \text { invariant }\end{array}$ & $\chi\left(141, N_{1}=498, N_{2}=356\right)=256.35$ \\
$v_{\mathrm{x}}$ invariant & $N=0.00$ & $\begin{array}{c}M_{4}-M_{3} \\
\chi_{d}^{2}(7)=4.68 \\
p>.05\end{array}$ \\
\hline
\end{tabular}

size of 854 ( $16 \%$ of the sample deleted). First, congeneric equivalence was assessed of system- and principle-level goals across segments with a confirmatory factor analysis. The model fit is good and therefore the hypothesis of congeneric equivalence cannot be rejected (see M1 in Table 4). Next, the hypothesis that goal dimensions in the model are on the same scale across segments was tested. This hypothesis can be accepted for both the ideal self and for the benefit constructs $\left(\chi_{d}^{2}(7)=7.71 ; p>.05\right)$. System-level and principle-level goals are tau-equivalent across groups, and further constraints can thus be tested. Both the hypotheses that the error terms $\left(\chi_{d}^{2}(13)=12.06 ; p>.05\right)$ and intercept terms are invariant 
Table 5. Factor Means for System and Principle Level Goals Across Segments.

\begin{tabular}{|c|c|c|c|c|}
\hline $\begin{array}{l}\text { System Level } \\
\text { Goals }\end{array}$ & Security & & ower & Self-direction \\
\hline $\begin{array}{l}\text { Premium car } \\
\text { buyer } \\
\text { Mass car buyer }\end{array}$ & $\begin{array}{c}0 \\
\text { Constrained } \\
0.12^{*} \\
t=2.86 \\
\end{array}$ & $\begin{array}{r}\text { Cons } \\
-( \\
t=\end{array}$ & $\begin{array}{l}0 \\
\text { trained } \\
.09^{*} \\
-2.06 \\
\end{array}$ & $\begin{array}{c}0 \\
\text { Constrained } \\
-0.07 \\
t=-1.55\end{array}$ \\
\hline $\begin{array}{l}\text { Principle Level } \\
\text { Goals }\end{array}$ & Safety & Economy & Comfort & Sporty Driving \\
\hline $\begin{array}{l}\text { Premium car buyer } \\
\text { Mass car buyer }\end{array}$ & $\begin{array}{c}0 \\
\text { Constrained } \\
-0.04 \\
t=-1.38\end{array}$ & $\begin{array}{c}0 \\
\text { Constrained } \\
0.93^{*} \\
t=19.88\end{array}$ & $\begin{array}{c}0 \\
\text { Constrained } \\
-0.15^{*} \\
t=-2.02\end{array}$ & $\begin{array}{c}0 \\
\text { Constrained } \\
-0.42^{*} \\
t=-6.96\end{array}$ \\
\hline
\end{tabular}

All tests of significance are two-tailed, ${ }^{*} p<0.05$.

across groups $\left(\chi_{d}^{2}(7)=4.68 ; p>.05\right)$ cannot be rejected for system- and principle-level goals. Hence the goal constructs are fully equivalent across segments in terms of key psychometric measurement criteria, and latent variable means can be estimated properly.

The factor mean for the system-level goal, self-direction, does not differ between the two segments (see Table 5). The factor mean for the system-level goal, power, is higher for consumers in the premium buyer segment. Consumers who mainly consider premium brands in car purchases possess a higher salience of the power motive in their ideal selves than consumers in the mass-market segment. Results for the system-level goal, power, are straightforward. Consumers who pursue power to a high degree in their ideal self are more likely to consider premium car brands as a means of achieving status differentiation. In contrast, the systemlevel goal, security, possesses higher salience for consumers who mainly consider mass-market brands. The system-level goal, security, has also a financial component. This is reflected through the item "... even now takes care of the financially security of his future and the future of his family." Consumers who strongly pursue security in their idealized self are less likely to consider expensive premium car brands, as this conflicts with their desire for financial security. Thus, the extent at which consumers pursue the two goals, security and power, differ between the two consumer segments defined by their patterns of brand consideration, partially confirming H2. Only the higher-order goal, self-direction, did not differ across segments. Still, it seems likely that not all higher-order goals will be determinants of benefits and market structure in a given product category.

H3 proposes that the salience of principle-level goals will differ across latent brand consideration segments and was partially confirmed. Consumers who consider premium brands put higher relevance on the principle-level goals, sporty driving and comfort, whereas the principle-level 
goal, economy, is clearly less salient for them. This result fits intuition. By contrast, the salience of the principle-level goal, safety, does not differ between the two segments. It is possible that safety is a hygiene need (Herzberg, 1966), which all brands fulfill to a satisfactory degree, so that the salience of this principle-level goal does not differ across brand consideration segments.

In order to probe more deeply into the functioning of goal hierarchies, an examination of structural relationships was performed between system- and principle-level goals. Of particular interest, an assessment was made whether the causal relations between system- and principle-level goals are invariant across segments. Thus for the model depicted in Figure $2,{ }^{1}$ invariance of causal relations between system-level and principle-level goals was tested. The hypotheses of structural invariance across segments cannot be rejected $\left(\chi^{2}{ }_{d}(8)=12.39 ; p>.05\right)$. Thus for the product category of this study, cars, it is the differing salience of system-level goals (here ideal selves) that results in the differential salience of principle-level goals, and not the differences in strength and/or direction of causal relations between goal levels.

However, significant mean differences on principle-level goals between premium and mass car buyer, after controlling for the mean differences on self-ideals, indicate that relevant system-level goals may have been omitted from the model of market structure for the product category at hand. Three motivational types from Schwartz's (1992) framework were measured herein, but other motivational types from the theory of human values might also be relevant for cars (e.g., hedonism).

Summing up, the findings support the notion that consumers regulate their behavior according to different levels of goals in their goal hierarchies. Differing salience of goals at different hierarchical levels lead, in turn, to different categorizations of brands. Thus, goals determine brand categorization and thereby also market structure and become antecedents

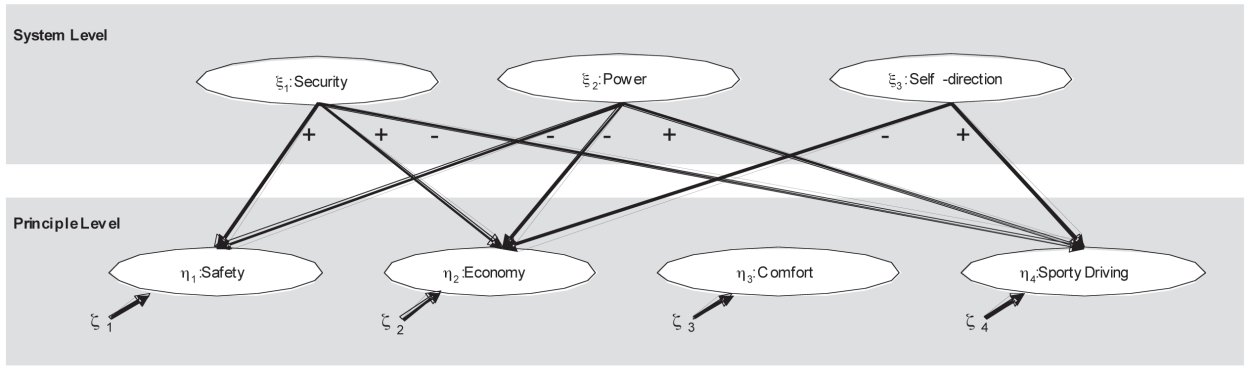

Figure 2. A goal hierarchy with two levels, as applied to automobile purchase decision making.

\footnotetext{
${ }^{1}$ A derivation of specific hypotheses concerning causal relationships between system- and principle-level goals can be found in Paulssen and Bagozzi (2005).
} 
of market structure. Market segments exist because consumers possess different goal orientations. As a result, the analysis of consumers' goal hierarchies answers the question of why a market has a certain structure.

\section{DISCUSSION}

A thorough market definition and market understanding are essential for marketing planning. It is important to derive models that can map whether all products in a market compete with each other or whether submarkets exist that have a high level of competition within and a low level of competition between them. Several researchers have suggested that the key to understanding competition, and hence product-market structure, is substitutability (e.g., Day et al., 1979). Following De Sarbo and Jedidi (1995), the approach taken in this article uses consideration sets for market structuring and conceptualizes segments as latent types of consumers with homogeneous consideration sets. Products or services are substitutes to the extent that buyers find products or services in the same consideration set to be equally desirable for a particular purpose.

A limitation with the De Sarbo and Jedidi (1995) study (as with the majority of market structuring approaches) is its descriptive nature, because it does not provide a rationale for modeling the process by which consideration sets are actually formed. In the present study, the self-regulatory model of consideration-set formation (see Paulssen \& Bagozzi, 2005) was applied to provide such a theory-based rationale. Building on recent research in MSA, this model of individual consumer behavior is based on the notion that consumer search and choice are goal-directed and purposive (Ratneshwar et al., 1999; Yang et al., 2002). Rather than giving a solely descriptive account of a market structure, it was attempted herein to provide a richer understanding of why a market has a certain structure. Consumers regulate their behavior according to different goal levels in their goal hierarchies. The different saliences of goals at different levels (i.e., the system level and principle level; see Figure 1) at which consumers regulate their behavior leads to different brand consideration sets.

On an aggregate level, individual differences in brand consideration determine the structure of a market. Thus, hierarchically organized goals determine brand consideration and are thereby antecedents of market structure. Market segments exist because consumers possess differing saliences of goals. This emphasis on goals is consistent with Haley's (1968) classic article in which he irrevocably linked market segmentation to consumer goals/motives. As has been demonstrated herein, consumer types (which were defined by their brand consideration) differ with respect to the salience of goals both at the system level and the principle level in their goal hierarchies, which regulate behavior. Employing the notion of goal hierarchies, this study was able to relate an abstract system-level goal, such as the ideal self, to market structure. Partial con- 
firmation of $\mathrm{H} 2$ also shows that not all higher-order goals are determinants of benefits and market structure in a given product category. Furthermore, not all benefits or principle-level goals differ in their salience across consumer types.

The majority of market structure models in the literature work with data characterizing purchase histories in frequently purchased consumer nondurables categories (e.g., Elrod et al., 2002). A shortcoming of these approaches is that consumer durables, such as appliances and automobiles, cannot be fruitfully modeled because these approaches can only be applied to goods with high purchase frequencies (Siddarth et al., 1995). Therefore, the approach developed in this article closes a gap in the literature in that market structuring with consideration sets and the selfregulatory model of consideration formation are especially applicable to high-involvement products with low purchase frequencies.

\section{Managerial Implications}

Several insights into market structure can be identified by use of the approach developed herein. First, segment-by-segment descriptions are obtained of the differences in consideration sets. These segment descriptions can help managers understand who they are competing against and how this competition varies by segment. The model characterizes competition between brands in a market and thereby provides a means of evaluating the effectiveness of marketing efforts and helps to identify new opportunities, for example, to identify where new products should be positioned. The study of the co-occurrence of competing brands among consideration sets can also alert managers to sources of "sister" cannibalization (Siddarth et al., 1995). The more that brands of the same company (e.g., VW, Audi) co-occur in consideration sets, the greater the chance that marketing activities will cannibalize the sales of sister brands.

Furthermore, the danger of potential competition through new competitors can be assessed under the approach proposed herein. In the market under study, BMW and Mercedes Benz should not be too concerned if Ford attempts to enter the premium segment with a new model, because at this point in time at least, the brand is not considered at all by premium customers. The success of Japanese premium brands (such as Lexus in the United States, and its comparatively lesser success in Europe) is also mirrored by the results. Consumers in the premium segment clearly do not consider Toyota, and therefore also may not consider the associated brand, Lexus. This preference barrier has been, and may well continue to be, difficult to overcome in Europe.

Second, the approach proposed herein provides a segment-by-segment account of the differences in benefits sought by customers and in the salience of an abstract higher-order goal, such as the ideal self. This information, coupled with the segment-by-segment account of brand consideration, gives a detailed picture of the strategic positioning of brands in a mar- 
ket and their strengths and weaknesses in comparison to key competitors. Audi, for example, has not yet achieved the status of a premium brand in Europe like Mercedes-Benz or BMW have. Customers, for whom selfideals of power and benefits, such as comfort and sporty driving, are particularly salient, have a clearly lower probability of considering Audi compared to such brands as BMW or Mercedes-Benz. Knowledge gained about hierarchical goal structures, which function as behavioral determinants of market structure, can help companies anticipate shifts in customer preferences that may lead to competitive advantages (Hunt \& Morgan, 1995).

As noted above, the majority of market structure approaches is based on behavioral outcome data, such as purchase frequencies recorded over time. As a consequence, a focus on the composition of consumers' consideration sets can be specifically beneficial in contexts where those data are not available or not applicable, such as with consumer durables. Other important application contexts are markets where the producer may risk technological obsolescence on account of emerging innovations in the marketplace. For example, Roberts and Morrison (2002) show the perceptual convergence of the product categories of home entertainment, personal computers, and telecommunication markets. Here a study of consideration sets could be valuable and managerially relevant to yield insights into what degree these different product categories are already perceived to be substitutes by different consumer groups (Shocker et al., 2004).

\section{Limitations}

Several limitations should be mentioned concerning the operationalizations of constructs. For completeness, it would have been desirable to include other motivational types from Schwartz's framework in the analysis. Another point that can be criticized is the two-step approach advocated by Anderson and Gerbing (1988). Given that no established scales for most of the constructs in our study have been used and validated to date, the authors believe that the two-step approach was an appropriate choice. Moreover, one limitation of the two-step approach was overcome by conducting cross-validations of the measurement model in a validation sample (Fornell \& Yi, 1992a, 1992b).

A limitation of all latent structure methods concerns the reality and actionability of latent segments. Certainly there are customers that only consider premium brands, whereas other customers may only consider mass-market brands. However, Cooper and Inoue (1996) point out that the reality of a latent class should be validated by other research before marketing-strategies are based on it.

Most of the work in the market structure area is based on the assumption that the market consists of a single product category composed only of substitutes (Shocker et al., 2004). However, there is empirical evidence that choice tasks may involve products from multiple categories (Ratneshwar, Pechmann, \& Shocker, 1996; Russell et al., 1999). Greater under- 
standing of the interrelationship between product categories can help marketers design better marketing strategies and tactics. Russell et al. (1999) propose several ways in which choices across categories can be linked. In all the cases mentioned by Russell et al., buyers' goals are central for the understanding of multiple category choice. The self-regulatory model of consideration-set formation, which served as the theoretical foundation of this article's MSA approach, is based on the notion of goal-oriented, purposive behavior on the part of consumers (e.g., Bagozzi \& Dholakia, 1999; Bagozzi \& Nataraajan, 2000). Goals are hypothesized to determine brand categorization and thereby market structure. The MSA approach developed in this article would therefore be specifically suited for modeling across-category consideration and choice. A fruitful avenue for future research would be to apply this approach to a multicategory choice situation. A potential example for studying intercategory effects might be the product categories of home entertainment, personal computers, and telecommunication markets, where technology-driven convergence is taking place (Roberts \& Morrison, 2002). With these product categories, a study of intercategory competition and its dynamics over time would be particularly interesting (Shocker et al., 2004).

\section{REFERENCES}

Aaker, D. A. (1998). Developing business strategies (5th ed.). New York: Wiley.

Anderson, J. C., \& Gerbing, D. W. (1988). Structural equation modeling in practice: A review and recommended two-step approach. Psychological Bulletin, 103, 411-423.

Bagozzi, R.P., \& Dholakia, U. (1999). Goal-setting and goal-striving in consumer behavior. Journal of Marketing, 63, 19-32.

Bagozzi, R. P., \& Nataraajan, R. (2000). The year 2000: Looking forward. Psychology \& Marketing, 17, 1-11.

Carver, C. S., \& Scheier, M. F. (1990). Origins and functions of positive and negative affect: A control-process view. Psychological Review, 97, 19-25.

Carver, C. S., \& Scheier, M. F. (1996). On the self-regulation of behavior. Cambridge, United Kingdom: Cambridge University Press.

Clogg, C. C. (1979). Some latent structure models for the analysis of Likert-type data. Social Science Research, 8, 287-301.

Clogg, C. C. (1995). Latent class models. In G. Arminger, C. C. Clogg, \& M. E. Sobel (Eds.), Handbook of statistical modeling for the social and behavioral sciences (pp. 311-359). New York: Plenum Press.

Collins, L. M., Fidler, P. L., Wugalter, S. E., \& Long, J. D. (1993). Goodness-of-fit testing for latent class models. Multivariate Behavioral Research, 28, 375-389.

Cooper, L. G., \& Inoue, A. (1996). Building market structure from consumer preferences. Journal of Marketing Research, 33, 293-306.

Day, G. S., Shocker, A. D., \& Srivastava, R. K. (1979). Customer-oriented approaches to identifying product markets. Journal of Marketing, 43, 8-19.

De Sarbo, W. S., \& Jedidi, K. (1995). The spatial representation of heterogenous consideration sets. Marketing Science, 14, 326-342. 
Despandé, R., \& Gatignon, H. (1994). Competitive analysis. Marketing Letters, 5, 271-278.

Dillon, W. R., \& Kumar, A. (1994). Latent structure and other mixture models in marketing: An integrative survey and overview. In R. P. Bagozzi (Ed.), Advanced methods of marketing research (pp. 295-351). Cambridge, United Kingdom: Blackwell.

Elrod, T., Russell, G. J., Shocker, A. D., Andrews, R. L., Bacon, L., Bayus, B. L., Carroll, J. D., Johnson, R. M., Kamakura, W. A., Lenk, P., Mazanec, J. A., Rao, V. R., \& Shankar, V. (2002). Inferring market structure from customer response to competing products. Marketing Letters, 13, 221-232.

Finn, A., \& Louviere, J. (1990). Shopping-center patronage models: Fashioning a consideration set segmentation solution. Journal of Business Research, 32, 259-275.

Forman, A. K. (1984). Die latent-class-analyse-einführung in theorie und anwendung. Weinheim: Beltz Verlag.

Fornell, C., \& Yi, Y. (1992a). Assumptions of the two-step approach to latent variable modeling. Sociological Methods \& Research, 20, 291-320.

Fornell, C., \& Yi, Y. (1992b). Assumptions of the two-step approach-reply to Anderson and Gerbing. Sociological Methods \& Research, 20, 334-339.

Goodman, L. A. (1974). Exploratory latent structure analysis using both identifiable and unidentifiable models. Biometrika, 61, 215-231.

Gronhaug, K., \& Troye, S. V. (1983). Exploring the content of the evoked set in car buying. European Research, 11, 98-104.

Haley, R. I. (1968). Benefit segmentation: A decision-oriented research tool. Journal of Marketing, 32, 30-35.

Hauser, J. R., \& Wernerfelt, B. (1989). The competitive implications of relevant-set/ response analysis. Journal of Marketing Research, 26, 391-405.

Herzberg, F. (1966). Work and the nature of man. Cleveland: World Publishing Company.

Holden, S. J. S. (1993). Understanding brand awareness: Let me give you a c(l)ue. Advances in Consumer Research, 20, 383-388.

Hunt, S. D., \& Morgan, R. M. (1995). The comparative advantage theory of competition. Journal of Marketing, 59, 1-15.

Jöreskog, K. G., \& Sörbom, D. (1996). LISREL 8: User's reference guide. Chicago: Scientific Software International, Inc.

Langeheine, R. (1988). New developments in latent class theory. In R. Langeheine \& J. Rost (Eds.), Latent trait and latent class models (pp. 77-108). New York: Plenum Press.

Langeheine, R., Pannekoek, J., \& Van de Pol, F. (1996). Bootstrapping goodness-offit measures in categorical data analysis. Sociological Methods \& Research, 24, 492-516.

Langeheine, R., Van de Pol, F., \& Pannekoek, J. (1997). Kontingenztabellen-analyse bei kleinen stichproben: Probleme bei der prüfung der modellgültigkeit mittels chi-quadrat statistiken. Empirische Pädagogik, 11, 63-77.

Nedungadi, P. (1990). Recall and consumer consideration sets: Influencing choice without altering brand evaluations. Journal of Consumer Research, 17, 263-275.

Nedungadi, P., Chattopahyay, A., \& Muthukrishnan, A. V. (2001). Category structure, brand recall and choice. International Journal of Research in Marketing, 18, 191-202.

Paulssen, M., \& Bagozzi, R. P. (2005). A self-regulatory model of consideration set formation. Psychology \& Marketing, 22, 785-812. 
Porter, M. E. (1979). The structure within industries and companies' performance. Review of Economics \& Statistics, 61, 214-227.

Punj, G., \& Brookes, R. (2001). Decision constraints and consideration-set formation in consumer durables. Psychology \& Marketing, 18, 843-863.

Punj, G., \& Brookes, R. (2003). The influence of pre-decisional constraints on information search and consideration set formation in new automobile purchases. International Journal of Research in Marketing, 19, 383-400.

Ratneshwar, S., Pechmann, C., \& Shocker, A. D. (1996). Goal-derived categories and the antecedents of across-category consideration. Journal of Consumer Research, 23, 240-250.

Ratneshwar, S., Shocker, A. D., Cotte, J., \& Srivastava, R. K. (1999). Product, person, and purpose: Putting the consumer back into theories of dynamic market behaviour. Journal of Strategic Management, 7, 191-208.

Roberts, J. H., \& Lattin, J. M. (1991). Development and testing of a model of consideration set composition. Journal of Marketing Research, 28, 429-440.

Roberts, J. H., \& Morrison P. D. (2002). Assessing market structure and company fit based on consumer perceptions in dynamic information technology markets. Journal of Business Research, 55, 679-686.

Russell, G. J., Ratneshwar, S., Shocker, A. D., Bell, D., Bodapati, A., Degeratu, A., Hildebrandt, L., Kim, N., Ramaswami, S., \& Shankar, V. H. (1999). Multiple category decision-making: Review and synthesis. Marketing Letters, 10, 319-332.

Schwartz, S. H. (1992). Universals in the content and structure of values: Theoretical advances and empirical tests in 20 countries. In M. Zanna (Ed.), Advances in experimental social psychology (Vol. 25, pp. 1-65). New York: Academic.

Schwartz, S. H., \& Boehnke, K. (2004). Evaluating the structure of human values with confirmatory factor analysis. Journal of Research in Personality, 38, 230-255.

Shocker, A. D., Bayus, B. L., \& Kim, N. (2004). Product complements and substitutes in the real world: The relevance of "other products." Journal of Marketing, 68, $28-40$.

Siddarth, S., Bucklin, R. E., \& Morrison, D. G. (1995). Making the cut: Modeling and analyzing choice set restrictions in scanner panel data. Journal of Marketing Research, 32, 255-266.

Van de Pol, F., Langeheine, R., \& De Jong, W. (1991). Panmark user manual. Voorburg: Netherlands Central Bureau of Statistics.

Yang, S., Allenby, G. M., \& Fennell, G. (2002). Modeling variation in brand preference: The roles of objective environment and motivating conditions. Marketing Science, 21, 14-31.

Correspondence regarding this article should be sent to: Richard P. Bagozzi, Ross School of Business and College of Pharmacy, University of Michigan, 701 Tappan, Ann Arbor, MI 48109-1234 (bagozzi@umich.edu). 
Appendix A1-1. Results Calibration Sample ( $t$ Values in Parentheses).

\begin{tabular}{llcccc}
\hline Item & Construct & $\lambda$ value & $\begin{array}{c}\text { Construct } \\
\text { Reliability }\end{array}$ & Mean & $S D$ \\
\hline $\begin{array}{l}\text { Absolutely safe driving } \\
\text { properties }\end{array}$ & Safety & $0.76(15.73)$ & $\xi_{1}: 0.82$ & 0.68 & 1.19 \\
$\begin{array}{l}\text { Highest possible safety in } \\
\text { accidents }\end{array}$ & Safety & $0.80(15.92)$ & & 0.68 & 1.17 \\
$\begin{array}{l}\text { 100\% reliability } \\
\begin{array}{l}\text { Extremely sporty driving } \\
\text { properties }\end{array}\end{array}$ & $\begin{array}{l}\text { Safety } \\
\text { driving }\end{array}$ & $0.76(14.00)$ & & 0.80 & 1.15 \\
$\begin{array}{l}\text { Extremely powerful engine } \\
\text { Extremely low cost of }\end{array}$ & $\begin{array}{l}\text { Sporty } \\
\text { driving }\end{array}$ & $0.79(11.69)$ & $\xi_{2}: 0.63$ & -0.67 & 1.71 \\
$\quad$ Economy & $0.75(10.58)$ & $\xi_{3}: 0.86$ & -0.16 & 1.82 \\
$\begin{array}{l}\text { Extremely low fuel } \\
\text { consumption }\end{array}$ & Economy & $0.97(13.39)$ & & -0.62 & 1.76 \\
\begin{tabular}{l} 
Very comfortable car \\
\hline
\end{tabular} & Comfort & $1.00(-)$ & $\xi_{4}:$ na & 0.10 & 1.19 \\
\hline
\end{tabular}

Appendix A1-2. Correlations (Below Diagonal), Chi-square Difference Tests (Above Diagonal).

\begin{tabular}{lcccc}
\hline Constructs & $\xi_{1}$ & $\xi_{2}$ & $\xi_{3}$ & $\xi_{4}$ \\
\hline$\xi_{1}$ & - & 67.19 & 87.70 & 49.43 \\
$\xi_{2}$ & -0.51 & - & 56.86 & 59.36 \\
$\xi_{3}$ & 0.14 & -0.51 & - & 56.25 \\
$\xi_{4}$ & -0.05 & -0.29 & .00 & - \\
\hline
\end{tabular}

Appendix A1-3. Models and Global Fit Measures.

\begin{tabular}{ll}
\hline Model & Global Fit Measures \\
\hline Calibration sample & $\chi^{2}(15)=25.38$, RMSEA $=.040, p($ RMSEA $<0.05)=.71$ \\
Validation sample-factor pattern similar & $\chi^{2}(15)=43.82$, RMSEA $=.066, p($ RMSEA $<0.05)=.11$ \\
Validation sample-lambdas equal & $\chi^{2}(19)=48.72$, RMSEA $=.060, p($ RMSEA $<0.05)=.20$ \\
Validation sample-all parameters equal & $\chi^{2}(36)=255.84$, RMSEA $=.12, p($ RMSEA $<0.05)=.00$ \\
\hline
\end{tabular}


Appendix A2-1. Results Calibration Sample ( $t$ Values in Parentheses).

\begin{tabular}{|c|c|c|c|c|c|}
\hline Item & Construct & $\lambda$ value & $\begin{array}{l}\text { Construct } \\
\text { Reliability }\end{array}$ & Mean & $S D$ \\
\hline $\begin{array}{l}\text { Even now takes care of the } \\
\text { financial security of his } \\
\text { future and the future of } \\
\text { his family. }\end{array}$ & Security & $\begin{array}{c}0.73 \\
(22.56)\end{array}$ & $\xi_{1}: 0.70$ & 3.16 & 0.82 \\
\hline $\begin{array}{l}\text { First priority is the well- } \\
\text { being of his family. }\end{array}$ & Security & $\begin{array}{c}0.73 \\
(22.56)\end{array}$ & & 3.28 & 0.76 \\
\hline $\begin{array}{l}\text { Wants to emphasize his } \\
\text { individual personality } \\
\text { particularly as opposite } \\
\text { to others. }\end{array}$ & Power & $\begin{array}{c}0.68 \\
(6.99)\end{array}$ & $\xi_{2}: 0.63$ & 2.88 & 0.87 \\
\hline $\begin{array}{l}\text { Wants to be respected and } \\
\text { admired by others. }\end{array}$ & Power & $\begin{array}{c}0.68 \\
(7.05)\end{array}$ & & 3.04 & 0.82 \\
\hline $\begin{array}{l}\text { Wants to be free and } \\
\text { independent and not to be } \\
\text { patronized by anybody. }\end{array}$ & Self-direction & $\begin{array}{c}0.74 \\
(6.77)\end{array}$ & $\xi_{3}: 0.75$ & 2.96 & 0.87 \\
\hline $\begin{array}{l}\text { Does not want to be } \\
\text { restricted in his freedom } \\
\text { of movement at all and } \\
\text { wants to go wherever he } \\
\text { wants to go. }\end{array}$ & Self-direction & $\begin{array}{c}0.81 \\
(6.93)\end{array}$ & & 3.09 & 0.79 \\
\hline
\end{tabular}

Appendix A2-2. Correlations (Below Diagonal), Chi-square Difference Tests (Above Diagonal).

\begin{tabular}{lccc}
\hline Constructs & $\xi_{1}$ & $\xi_{2}$ & $\xi_{3}$ \\
\hline$\xi_{1}$ & - & 56.99 & 99.97 \\
$\xi_{2}$ & 0.22 & - & 52.99 \\
$\xi_{3}$ & 0.07 & 0.30 & - \\
\hline
\end{tabular}

Appendix A2-3. Models and Global Fit Measures.

\begin{tabular}{lc}
\hline Model & Global Fit Measures \\
\hline Calibration sample & $\chi^{2}(7)=12.32$, RMSEA $=.039, p($ RMSEA $<0.05)=.64$ \\
Validation sample—factor pattern similar & $\chi^{2}(7)=15.87$, RMSEA $=.051, p($ RMSEA $<0.05)=.43$ \\
Validation sample-lambdas equal & $\chi^{2}(9)=22.15$, RMSEA $=.055, p($ RMSEA $<0.05)=.35$ \\
Validation sample-all parameters equal & $\chi^{2}(21)=46.00$, RMSEA $=.049, p($ RMSEA $<0.05)=.49$ \\
\hline
\end{tabular}

